\title{
Neocallimastix frontalis enolase gene, enol: first report of an intron in an anaerobic fungus
}

\author{
R. Durand, M. Fischer, C. Rascle and M. Fèvre \\ Author for correspondence: R. Durand. Tel: +33724485 42. Fax: +33 72431181 .
}

Laboratoire de Biologie Cellulaire Fongique, Centre de Génétique Moléculaire et Cellulaire, CNRS UMR 106, Băt. 405, Université Lyon I, 69622 Villeurbanne Cedex France

\begin{abstract}
A DNA clone containing a putative enolase gene was isolated from a genomic DNA library of the anaerobic fungus Neocallimastix frontalis. It was deduced from sequence comparisons that the enolase gene was interrupted by a large 331 bp intron. The enolase gene, termed enol, has an ORF of 1308 bp and encodes a predicted 436 amino acid protein. The deduced amino acid sequence shows high identity $(71.5-71 \%)$ to those of enolases from the yeasts Saccharomyces cerevisiae and Candida albicans. The $\mathbf{G}+\mathbf{C}$ content of the enolase coding sequence $(43.8 \mathrm{~mol} \%)$ is considerably higher than the $\mathbf{G}+\mathrm{C}$ content of the intervening sequence $(14.2 \mathrm{~mol} \%)$ or the $5^{\prime}$ and $3^{\prime}$ non-translated flanking sequences $(15 \cdot 2$ and $4.7 \mathrm{~mol} \%$, respectively). The codon usage of the $N$. frontalis enolase gene was very biased as has been found for the highly expressed genes of yeast and filamentous fungi. The gene has all the canonical features (polyadenylation signal, intron splicing boundaries) of genes isolated from aerobic filamentous fungi. Only one enolase gene could be detected in $\boldsymbol{N}$. frontalis genomic DNA by Southern analysis with a homologous probe. RNA analysis detected a single enolase transcript of about $1.6 \mathrm{~kb}$. When mycelium was grown on glucose, levels of enolase mRNA were markedly increased by comparison with enolase mRNA levels in mycelium grown on cellulose, suggesting that expression of the $\boldsymbol{N}$. frontalis enolase gene was transcriptionally regulated by the carbon source.
\end{abstract}

Keywords: enolase, anaerobic fungus, rumen, Neocallimastix frontalis

\section{INTRODUCTION}

Although the main diet of herbivorous mammals is plant material, they are totally dependent on the microorganisms in their digestive tracts to break complex polysaccharides into small molecules prior to absorption. Rumen bacteria, protozoa and fungi are the main contributors to the process of digestion. The anaerobic fungus Neocallimastix frontalis, first isolated from the sheep rumen by Orpin (1975), has been intensively studied for its large production of a wide range of glycoside and polysaccharide hydrolases (Hébraud \& Fèvre, 1988). In axenic culture, $N$. frontalis can utilize several monosaccharides and plant cell-wall polymers as carbon sources (Li \& Heath, 1993). The fermentation of glucose by $N$. frontalis proceeds via the Embden-Meyerhof-Parnas pathway (Marvin-Sikkema et al., 1993). Enzyme activities leading to the formation of succinate, lactate, ethanol and

The EMBLGenBank accession number for the nucleotide sequence reported in this paper is $X 80474$. formate are associated with the cytoplasmic fraction, while the enzymes leading to the formation of the main fermentation products $\mathrm{H}_{2}, \mathrm{CO}_{2}$, acetate and the production of ATP are localized in microbodies identified as hydrogenosomes.

$N$. frontalis has been used as a model to clone the genes expressed during the hydrolysis of complex cell-wall polysaccharides. A differential screening of a cDNA library lead to the isolation of several clones which were highly expressed during growth on cellulose. Several of these clones have been characterized by restriction analysis, partial sequencing and Northern blotting (Reymond et al., 1991). Three cDNAs have been identified as clones encoding enzymes of the glucose fermentation pathway: phosphoenolpyruvate carboxykinase (Reymond et al., $1991)$, hydrogenosomal $\beta$-succinyl-CoA synthetase (unpublished results) and enolase (this study).

Enolase (2-phospho-D-glycerate hydro-lyase, EC 4.2.1.11) is a ubiquitous enzyme that catalyses the conversion of 2-phosphoglycerate to phosphoenolpyruvate, the only dehydration step of the glycolytic 
pathway. Enolase genes have been cloned from different sources: the yeasts Saccharomyces cerevisiae (Holland et al., 1981) and Candida albicans (Brett Mason et al., 1993), the human malaria parasite Plasmodium falciparum (Read et al., 1994), higher plants such as tomato and Arabidopsis (Van der Straeten et al., 1991), and several animals such as rat and chicken. In avian and mammalian tissues, three types of enolase isoenzyme ( $\alpha, \beta$ and $\gamma$ ) have been described, and the active form of the enzyme is a homodimer or a heterodimer as a consequence of the expression of genes in a tissue- and development-specific manner (Segil et al., 1988). The enzyme from $S$. cerevisiae is by far the best characterized and its crystal structure has been determined (Lebioda et al., 1989). Two structural genes, ENO1 and ENO2, are expressed differentially in yeast cells grown on glucose and in cells grown on gluconeogenic carbon sources. ENO2 is induced more than 20 -fold in cells grown on glucose, whereas ENO1 expression is similar in cells grown on glucose or on gluconeogenic carbon sources (Cohen et al., 1986). Complex cis-acting regulatory sequences that bind distinct trans-acting factors have also been identified (Cohen et al., 1987; Carmen \& Holland, 1994).

In spite of the isolation of various cDNAs, very little information is available on gene organization in rumen anaerobic fungi. A $3 \mathrm{~kb}$ genomic clone carrying the endoglucanase gene $c e l \mathrm{~B}$ from the related species Neocallimastix patriciarum was analysed by Zhou et al. (1994) and found to contain no intron. This paper describes the characterization of a genomic clone of the $N$. frontalis enolase gene. The primary structure of the enolase sequence of this filamentous fungus is compared with the yeast, plant and animal counterparts. To our knowledge, this is the first gene containing an intron isolated from an anaerobic fungus, so it was of interest to compare its organization to those of aerobic fungi. The overall organization of the enolase gene (intervening sequence, intron boundaries, polyadenylation sequence, codon usage) was found to be very similar to the organization of other genes from filamentous aerobic fungi.

\section{METHODS}

Strains, plasmids, phage and media. N. frontalis $\mathrm{MCH} 3$, isolated from sheep (Laboratoire de Microbiologie CRZV, INRA, Theix, France) was grown anaerobically at $39^{\circ} \mathrm{C}$ for $2-5 \mathrm{~d}$ in culture flasks containing $500 \mathrm{ml}$ synthetic liquid medium (Lowe et al., 1987) supplemented with $1.5 \%$ (w/v) glucose or $0.6 \%(\mathrm{w} / \mathrm{v})$ Avicel as carbon sources. S. cerevisiae strain MD4014C (a bis 3-11 bis 3-15 leu 2-3 leu 2-112 trp1 ura2 $2 \mu^{+}$) provided by J. L. Souciet (IBMC Strasbourg, France) was grown at $30^{\circ} \mathrm{C}$ in liquid medium: $10 \mathrm{~g}$ yeast extract $\mathrm{l}^{-1}, 20 \mathrm{~g}$

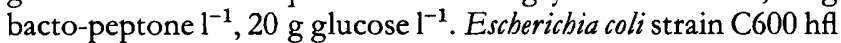
[e14-(mor $A)$ supE44 thi-1 thr1 leuB6 lacY1 ton $A 21$ bfl $A 150:: \operatorname{Tn} 10]$ was used for the propagation of the $\lambda 1149$ cDNA bank and maintained on BBL medium (Maniatis $e t$ al., 1982).

E. coli strain XL1-Blue from Stratagene $[\operatorname{rec} A 1$ end $A 1$ gyr $A 96$ thi-1 bsdR17 supE44 rel $A 1$ lac $\left(\mathrm{F}^{\prime}\right.$ pro $A B$ lacl ${ }^{\mathrm{a}} \mathrm{Z} \Delta \mathrm{M} 15$ Tn 10 tet $\left.\left.^{\mathrm{r}}\right)\right]$ was used for the construction of the genomic library and the Lambda Zap cDNA bank, and the propagation and ampli- fication of hybrid pBluescript plasmids. All the XL-1 Blue cultures were on NZY medium (Maniatis et al., 1982).

Construction of a genomic bank of $\boldsymbol{N}$. frontalis. Mycelium of $N$. frontalis was harvested by centrifugation, frozen in liquid nitrogen and freeze-dried. The dried mycelium was ground in a mortar in the presence of liquid nitrogen and resuspended in $10 \mathrm{ml}$ extraction buffer $(0.2 \mathrm{M}$ Tris/ $\mathrm{HCl}, \mathrm{pH} 7 \cdot 6,0.025 \mathrm{M} \mathrm{NaCl}$, $0.025 \mathrm{M}$ EDTA, $0.5 \% \mathrm{SDS}, 400 \mathrm{mg} \mathrm{ml}^{-1}$ proteinase $\mathrm{K}$ ) per $\mathrm{g}$ dry material. After $30 \mathrm{~min}$ incubation at $65^{\circ} \mathrm{C}$, the contaminating proteins were extracted with chloroform and the DNA was precipitated from the upper aqueous phase by 0.7 vol. isopropanol. The DNA pellet was resuspended in $4 \mathrm{ml} \mathrm{TE}$ (Maniatis et al., 1982) and precipitated in the presence of $11.25 \%$ (w/v) PEG 6000. The DNA pellet was collected by centrifugation (10 $\mathrm{min}, 12000 \mathrm{~g}$ ) resuspended in TE and precipitated by 5 vols ethanol in the presence of 1 vol. $5 \mathrm{M}$ ammonium acetate at $-20^{\circ} \mathrm{C}$; after centrifugation $(30 \mathrm{~min}, 12000 \mathrm{~g})$ the DNA was resuspended in $\mathrm{H}_{2} \mathrm{O}$.

The low quantity of DNA recovered (1 mg per $20 \mathrm{~g}$ fresh mycelium) and the average size of the isolated DNA $(20-30 \mathrm{~kb})$ excluded a gradient size separation of restriction fragments. It was decided to use an insertion phage $\lambda$ Zap II (Stratagene) to construct the genomic library. Genomic DNA (30 $\mu \mathrm{g})$ was digested to completion by an overnight incubation with $10 \mathrm{U}$ $X b a l$ (Boehringer) and purified by phenol/chloroform extraction and ethanol precipitation. The genomic fragments were ligated in the $\lambda$ Zap arms and the recombinant phages were packaged in vitro according to the manufacturer's instructions.

Cloning and sequencing of the enolase gene. The $\lambda$ Zap and $\lambda 1149 \mathrm{cDNA}$ libraries that were previously constructed by Reymond et al. (1991) and the genomic library were screened by colony hybridization with the $\left[\alpha^{32} \mathrm{P}\right] \mathrm{dCTP}$-labelled $1.3 \mathrm{~kb}$ EcoR 1 incomplete enolase cDNA as a probe. This cDNA clone was previously isolated from a cDNA library (Reymond $e t$ al., 1991) and was identified by sequencing as a truncated cDNA enolase clone. The genomic inserts of positive plaques were isolated by in vivo excision using the helper phage R408 (Stratagene). After localization of the enol gene on the genomic clone by Southern hybridization, using the incomplete cDNA clone as a probe, subclones of this genomic fragment were constructed by conventional methods (Maniatis et al., 1982).

Nucleotide sequences were determined by the dideoxy chaintermination method (Sanger et al., 1977) on different templates: double-standed DNA, single-stranded DNA produced from the pBluescript plasmid (Stratagene), and deleted clones produced by unidirectional ExoIII digestion (Erase-a-Base, Promega) according to the manufacturer's instructions. When necessary, synthetic oligonucleotides were used to confirm the sequence. Sequence analyses were made by the Bisance computer programs (Dessen et al., 1990).

Southern analysis. S. cerevisiae chromosomal DNA was isolated as described by Johnston (1988). $N$. frontalis and $S$. cerevisiae DNAs were digested to completion with the appropriate endonucleases and the resulting fragments were fractionated by electrophoresis on a $0.8 \%$ agarose gel and transferred to nitrocellulose membranes (Schleicher \& Schuell). DNA probes were labelled with $\left[\alpha{ }^{32} \mathrm{P}\right] \mathrm{dCTP}\left(111 \mathrm{TBq} \mathrm{mmol}^{-1}\right.$, Amersham) by use of a random-primed labelling kit (Pharmacia). The DNA on the blots was hybridized with DNA probes at $42{ }^{\circ} \mathrm{C}$ in the presence of $50 \%(\mathrm{v} / \mathrm{v})$ formamide as recommended by the manufacturer.

After hybridization the membranes were washed twice for 20 min each time with $2 \times$ SSC, $0 \cdot 1 \%$ SDS and $0 \cdot 2 \times$ SSC, $0 \cdot 1 \%$ 
SDS. The washing temperature was $65^{\circ} \mathrm{C}$ for the homologous probing ( $N$. frontalis DNA blot) and $55^{\circ} \mathrm{C}$ for the heterologous probing ( $S$. cerevisiae DNA blot).

Northern analysis of $\boldsymbol{N}$. frontalis RNA. Total RNA was isolated as described by Chirgwin et al. (1979). RNA (30 $\mu$ g) were fractionated on a $1.2 \%(\mathrm{w} / \mathrm{v})$ agarose gel in denaturing conditions (Maniatis et al., 1982), and transferred to nitrocellulose membrane using the Northern procedure (Maniatis $e t$ al., 1982). DNA probes were labelled with $\left[\alpha-{ }^{32} \mathrm{P}\right] \mathrm{dCTP}$ by the random primer-labelling method (Feinberg \& Vogelstein, 1983) using a Pharmacia kit. Hybridization was performed according to standard procedures (Maniatis et al., 1982): hybridization was done at $42{ }^{\circ} \mathrm{C}$ in the presence of $50 \%$ formamide, $5 \times \mathrm{SSC}$, $1 \times$ Denhardt's solution, $20 \mathrm{mM}$ sodium phosphate buffer, $\mathrm{pH} 6.8,0.2 \%$ SDS and $200 \mu \mathrm{g}$ yeast tRNA ml ${ }^{-1}$; membranes were washed twice, for $20 \mathrm{~min}$ each time, at $42{ }^{\circ} \mathrm{C}$ with $2 \times \mathrm{SSC}$, $0.1 \%$ SDS and $0.2 \times \operatorname{SSC} 0.1 \%$ SDS, and exposed to autoradiographic film. The membranes were then washed in $0 \cdot 1 \times \mathrm{SSC}, 0 \cdot 1 \% \mathrm{SDS}$ at $95^{\circ} \mathrm{C}$ and re-hybridized with an rRNA genomic probe (R.D., unpublished results). The resultant autoradiograms were analysed by densitometry using the Gel Reader program (Appligene).

\section{RESULTS}

\section{Cloning and sequencing of $\boldsymbol{N}$. frontalis enolase gene}

A $1.3 \mathrm{~kb}$ cDNA clone, pPR6.1, previously isolated by Reymond et al. (1991), was sequenced and identified by sequence comparisons in the databases as an enolase clone. The deduced amino acid sequence of the cDNA clone had $69 \%$ identity with the amino acid sequence from position 110 to 432 of ENO1 from S. cerevisiae (Holland et al., 1981) and the $5^{\prime}$ part of the N. frontalis cDNA clone was missing. Several screenings of the two cDNA banks ( $\lambda 1149, \lambda$ Zap) did not lead to the isolation of a complete enolase cDNA clone. The partial cDNA clone pPR6.1 was used as a probe to screen a $\lambda$ Zap genomic DNA library; from $44 \cdot 10^{3}$ plaques, four positive plaques were identified which had the same restriction pattern. One clone pRDXX6.5 contained a $6.5 \mathrm{~kb}$ DNA

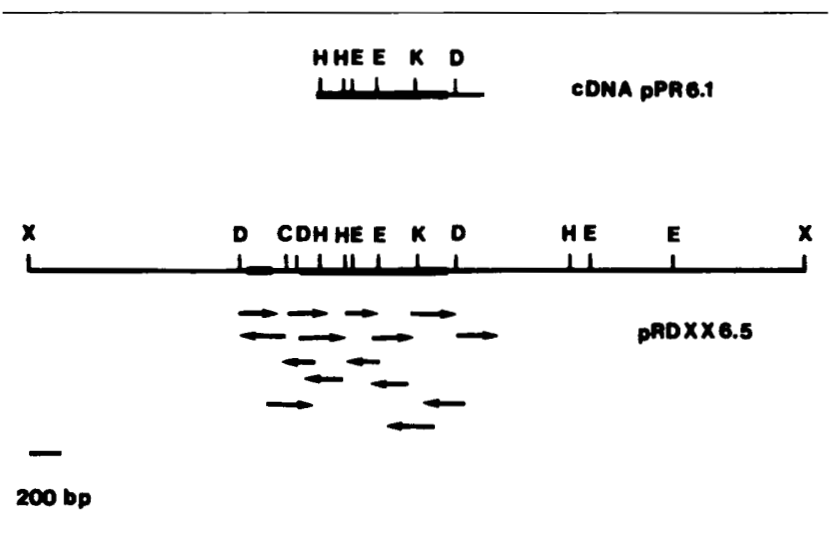

Fig 1. Restriction map of the $N$. frontalis enolase clone and sequencing strategies. The coding region of the enol gene and the partial enolase cDNA are indicated by shaded bars. Arrows indicate the positions and directions of sequencing. $C, C l a l ; D$, Dral; E, ECoRI; H, HindIII; K, Kpnl; X, Xbal. insert and was used for further analysis. A number of overlapping restriction fragments from this clone hybridized to the cDNA pPR6.1 (data not shown) indicating that the genomic clone contained the enolase gene and large flanking sequences (Fig. 1). The nucleotide sequence of the $2.8 \mathrm{~kb}$ DraI-HindIII fragment of the pRDXX6.5 was determined (Fig. 2). The identification of the clone was confirmed by sequence analysis and comparisons with the NBRF database. The deduced amino acid sequence was identified as encoding an enolase on the basis of its high homology with the $S$. cerevisiae ENO1 and ENO2 sequences. By comparing the nucleotide and amino acid sequence with those from $S$. cerevisiae, one intron was assumed to be present in the coding region.

A large sequence $(331 \mathrm{bp})$ from position +161 to +512 bp (relative to the first start codon) had intronsplicing boundaries matching the consensus sequences found in filamentous fungal genes (Gurr et al., 1987). The splicing signals were GTAAGT and TAG for the $5^{\prime}$ and $3^{\prime}$ intron boundaries, respectively, compared with the GTANGT and PyAG fungal consensus sequences. An internal sequence, TACTTAAA (+306 to $+313 \mathrm{bp}$ ), presumed to be involved in lariat formation, showed some similarity with the sequence PyGCTAACN of other fungal genes (Gurr et al., 1987). Assuming this to be an intron, the deduced amino acid sequence of the coding region showed a high overall identity to those of $S$. cerevisiae ENO1 and ENO2 (71.5 and $71 \%$, respectively). Therefore, we concluded that this gene does indeed encode an $N$. frontalis enolase; this gene was termed enol.

At the $3^{\prime}$ end of the DNA sequence from bases +1742 to +1747 , there is a putative AATAAA polyadenylation signal typical of higher eukaryotic genes (Fig. 2).

The $\mathrm{G}+\mathrm{C}$ content of the coding sequence of enolase is $43.8 \mathrm{~mol} \%$, while the $5^{\prime}$ and $3^{\prime}$ flanking sequences and the intervening sequence have a much lower $\mathrm{G}+\mathrm{C}$ content of $4 \cdot 7,15$ and $14 \mathrm{~mol} \%$, respectively. This base compostion is strongly divergent from that of an aerobic fungus as indicated by the data of statistical analysis of Neurospora genes, revealing that coding and non-coding sequences have a G $+\mathrm{C}$ content of 59 and $46 \mathrm{~mol} \%$, respectively (Edelmann \& Staben, 1994).

The 1308 bp ORF encoded a polypeptide of 436 amino acids with a predicted molecular mass of $47 \mathrm{kDa}$. The deduced amino acid sequence of the pPR6.1 cDNA showed $100 \%$ identity to the corresponding part of the enolase gene (data not shown). The codon usage of the $N$. frontalis enol gene was highly biased, with only 36 codons used of the possible 61 sense codons (Table 1). The unused codons always end in A or G. If a purine is present in the third position, $A$ is used in preference to $G$ with the exception of lysine ( $100 \%$ AAG).

\section{Comparisons of amino acid sequences}

The alignment of the predicted enolase proteins from a representative range of organisms is shown in Fig. 3, and 


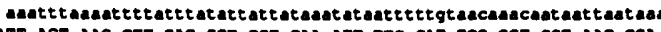
ATG GCT ATT ACT AMG GTT CAC GCT CGT CA ATT TTC GAT TCC CGT GGT AAC CCA

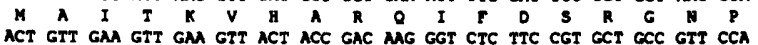
$T$ V E $V$ E GTY ACT ACC GAC MAG GGT CTC TTC CGT GCT GCC GTT CCA TCT GGT GCT TCC ACT GGT GIT CAC GM OCT CTT GAA CTC CGT GAT OGA AIT MAG TCT GGT GCT TCC ACT GGT GTT CAC GM GCT CTT GAA CTC CGT GAT OGA ATT MAG

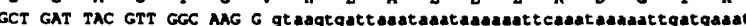
GCT GAT TAC GTT GGC AAC

Aat D Y Y V G K C a

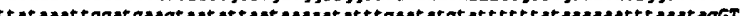

GTC TTA AAG GCT GTT GM AAC GTT MAC MAG ACT ATT OCC CCA GCT CTT GTT GCT GTC TTA AAG GCT GTT GAM AAC GTT AAC MAG ACT ATT GCC CCA GCT CTT GTT GCT GCC AAT CTT GAT GTT AMG AAC CM AAG OCT GTC GAT GAC ITC CTT CTI MG TTA

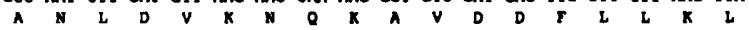
GAT GGT ACT CCA MAC MGG AGT AAG CTT GGT GCT AMC GCC ATC CTT GGT GTT TCC $D$ G I P N $X$ S $X$ L $G$ G N A I L G V S CTT GCT GTT GCC CGT GCT GGT GCT GCT GAT AAG GGT GTC CCA CTT TAC CAA CAC $L A V V A$ R A G A A D K G V P I Y $Q$ TTA GGT GAA TTA GCC GGT AAC AAG GGT CCA TGG ATT CTT CCA GTT CCA TCC ATG

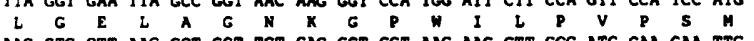
AAC GTC CTT AAC GGT GGT TCT CAC GCT GGT AAC AAG CTT GCC ATG CAA GAA TTC $N$ V L N G G G H

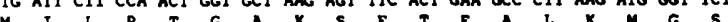

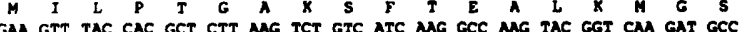

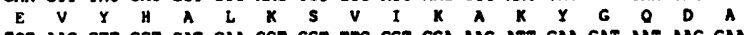
TGT AAC GTT GGT GAT GMA GGT GGT TTC CCT CCA AAC ATT CAA GAT MAT AMG GA

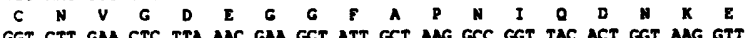
$G$ E $L$ L G L E E L L $\begin{array}{llllllllllllllllll}K & I & G & M & D & V & A & S & S & E & F & Y & K & D & G & K & Y & D\end{array}$ CTT GAC TTC AAG AAT CCA AAC TCT GAC CCA TCC AAG TEG ATC TCT GGT GAN GAA

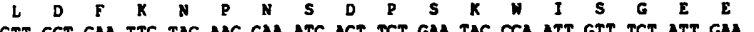

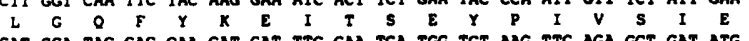
GAT CCA TAC GAC CM GAT GAT TTC GA TCA TGG TCT MG TTC AGA GCT GAT ATG 1270

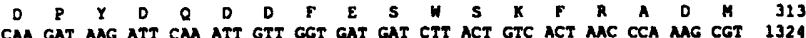

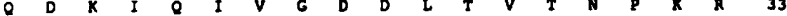
ATT GCT ATG GCT ATT GAN AAG AAG GCC TGT AMC GGT CTT TTA ITA MAG GTT MAC 1378

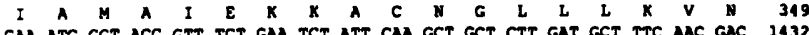

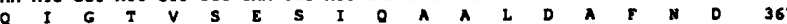
GGT TGG GGT GTT ATG GTT TCT CAC CGT TCT GGT GAA ACT GAA GAC ACT TTC ATT 1486

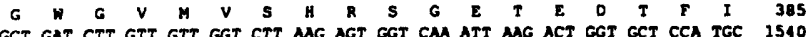
GCT GAT CTT GTT GTT GGT CTT AAG AGT GGT CAA ATT AAG ACT GGT GCT CCA TGC 1540

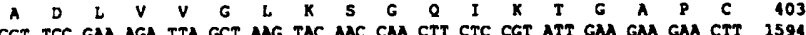
$\begin{array}{lllllllllllllllllll}R & S & E & R & L & A & K & Y & N & Q & L & L & R & I & E & E & E & L & 121\end{array}$ GGT GCT AAC GCT ACC TAC GCA GGT GAA MAC TTC CGT CGT CCA TTC TMA attaatt 164

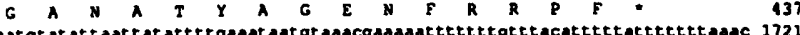

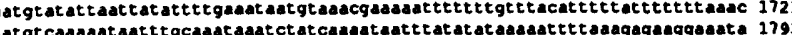

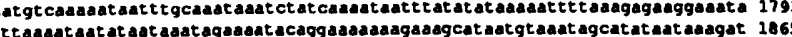

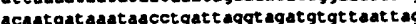

Fig 2. Nucleotide and deduced amino acid sequences of the enol gene of $N$. frontalis. The entire nucleotide sequence of enol gene is shown with the corresponding amino acid sequence printed below it. The nucleotide and amino acid sequences are numbered in front of each respective line. The $A$ of the putative ATG initiation codon is designated +1 , the stop codon is indicated by an asterisk. Lower case letters indicate nucleotides in non coding parts of the enol gene. The EMBL/GenBank accession number for the nucleotide sequence is $\mathrm{X} 80474$.

the levels of amino acid identity are presented in Table 2. Homology has been retained throughout the protein and there are numerous regions of complete identity in the 11 sequences analysed. The 187 invariant amino acids are arranged in short tracts of highly conserved sequences.

The lowest level of identity is seen with the enolase of plants (68-69\% identity), which had an insertion of the pentapeptide sequence EWGWC, while all the other enolases lack this motif.

The enolase sequences most similar to $N$. frontalis enolase are those of the yeasts $S$. cerevisiae and $C$. albicans $(70-71 \%$ identity). The dendrogram deduced from alignment of the enolase sequences (Fig. 4) demonstrated the presence of three families corresponding to fungal (yeast, Candida),

Table 1. Codon usage of the enol gene from $N$. frontalis

\begin{tabular}{|llllllll|}
\hline F TTT & $0 \cdot 0$ & S TCT & $3 \cdot 2$ & Y TAT & $0 \cdot 0$ & C TGT & $0 \cdot 5$ \\
F TTC & $3 \cdot 4$ & S TCC & $1 \cdot 6$ & Y TAC & $2 \cdot 8$ & C TGC & $0 \cdot 2$ \\
L TTA & $1 \cdot 8$ & S TCA & $0 \cdot 2$ & * TAA & $0 \cdot 2$ & * TGA & $0 \cdot 0$ \\
L TTG & $0 \cdot 0$ & S TCG & $0 \cdot 0$ & * TAG & $0 \cdot 0$ & W TGG & $0 \cdot 9$ \\
L CTT & $5 \cdot 7$ & P CCT & $0 \cdot 0$ & H CAT & $0 \cdot 0$ & R CGT & $2 \cdot 5$ \\
L CTC & $0 \cdot 9$ & P CCC & $0 \cdot 0$ & H CAC & $1 \cdot 4$ & R CGC & $0 \cdot 0$ \\
L CTA & $0 \cdot 0$ & P CCA & $3 \cdot 9$ & Q CAA & $3 \cdot 2$ & R CGA & $0 \cdot 0$ \\
L CTG & $0 \cdot 0$ & P CCG & $0 \cdot 0$ & Q CAG & $0 \cdot 0$ & R CGG & $0 \cdot 0$ \\
I ATT & $4 \cdot 4$ & T ACT & $3 \cdot 4$ & N AAT & $0 \cdot 7$ & S AGT & $0 \cdot 7$ \\
I ATC & $1 \cdot 1$ & T ACC & $0 \cdot 7$ & N AAC & $4 \cdot 8$ & S AGC & $0 \cdot 0$ \\
I ATA & $0 \cdot 0$ & T ACA & $0 \cdot 0$ & K AAA & $0 \cdot 0$ & R AGA & $0 \cdot 5$ \\
M ATG & $2 \cdot 1$ & T ACG & $0 \cdot 0$ & K AAG & $8 \cdot 5$ & R AGG & $0 \cdot 0$ \\
V GTT & 6.0 & A GCT & $7 \cdot 3$ & D GAT & $5 \cdot 0$ & G GGT & $9 \cdot 2$ \\
V GTC & $1 \cdot 4$ & A GCC & 3.0 & D GAC & $1 \cdot 6$ & G GGC & $0 \cdot 2$ \\
V GTA & 0.0 & A GCA & $0 \cdot 2$ & E GAA & $6 \cdot 7$ & G GGA & $0 \cdot 2$ \\
V GTG & 0.0 & A GCG & $0 \cdot 0$ & E GAG & $0 \cdot 0$ & G GGG & $0 \cdot 0$ \\
\hline
\end{tabular}

animals (Drosophila, chicken, human) and plant enolases (tomato, maize, Arabidopsis). In the fungal family, the enolase sequence of $N$. frontalis is clearly divergent from the yeast enolases.

\section{Copy number and expression of enol}

Multiple enolase genes have been demonstrated in several eukaryotic species; evidence of additional enolase genes was sought in $N$. frontalis by Southern analysis. A $2.4 \mathrm{~kb}$ Xbal-HindIII fragment from the clone pRDXX6.5 (Fig. 1 ), which includes the $5^{\prime}$ flanking sequence and overlaps the $5^{\prime}$ part of the $N$. frontalis enol gene, was hybridized against genomic DNA digested with BamHI, Xbal, EcoRI and HindIII, (Fig. 5). As XbaI and BamHI have no cleavage site within the enol gene, each hybridization band should represent a unique enolase gene. HindIII and EcoRI have a single cleavage site in the $5^{\prime}$ part of the enolase gene and the flanking sequence overlapped by the probe (Fig. 1). The size of the DNA fragments hybridizing to the probe were 2.5 and $2.7 \mathrm{~kb}$, respectively, indicating that the HindIII and EcoRI sites are closed to the Xbal site of the clone pSKXX6.5 in an adjacent genomic clone. The presence of only one band strongly suggested that there is only a single enolase gene in the $N$. frontalis genome.

The partial cDNA clone for $N$. frontalis enolase was used to probe the genomic DNA from $S$. cerevisiae digested with BamHI and Xbal. Neither of these enzymes has a cleavage site within the $S$. cerevisiae ENO1 or ENO2 genes. Two fragments of the $S$. cerevisiae were recognized by the probe, confirming the high degree of similarity between the $N$. frontalis enol and the two $S$. cerevisiae genes (Fig.5).

The effects of different carbon sources of the culture medium on expression of the $N$. frontalis enol gene were investigated by growing the fungus in the presence of glucose, crystalline cellulose (Avicel) or methylglucose (known as high-level inducers of secreted polysac- 


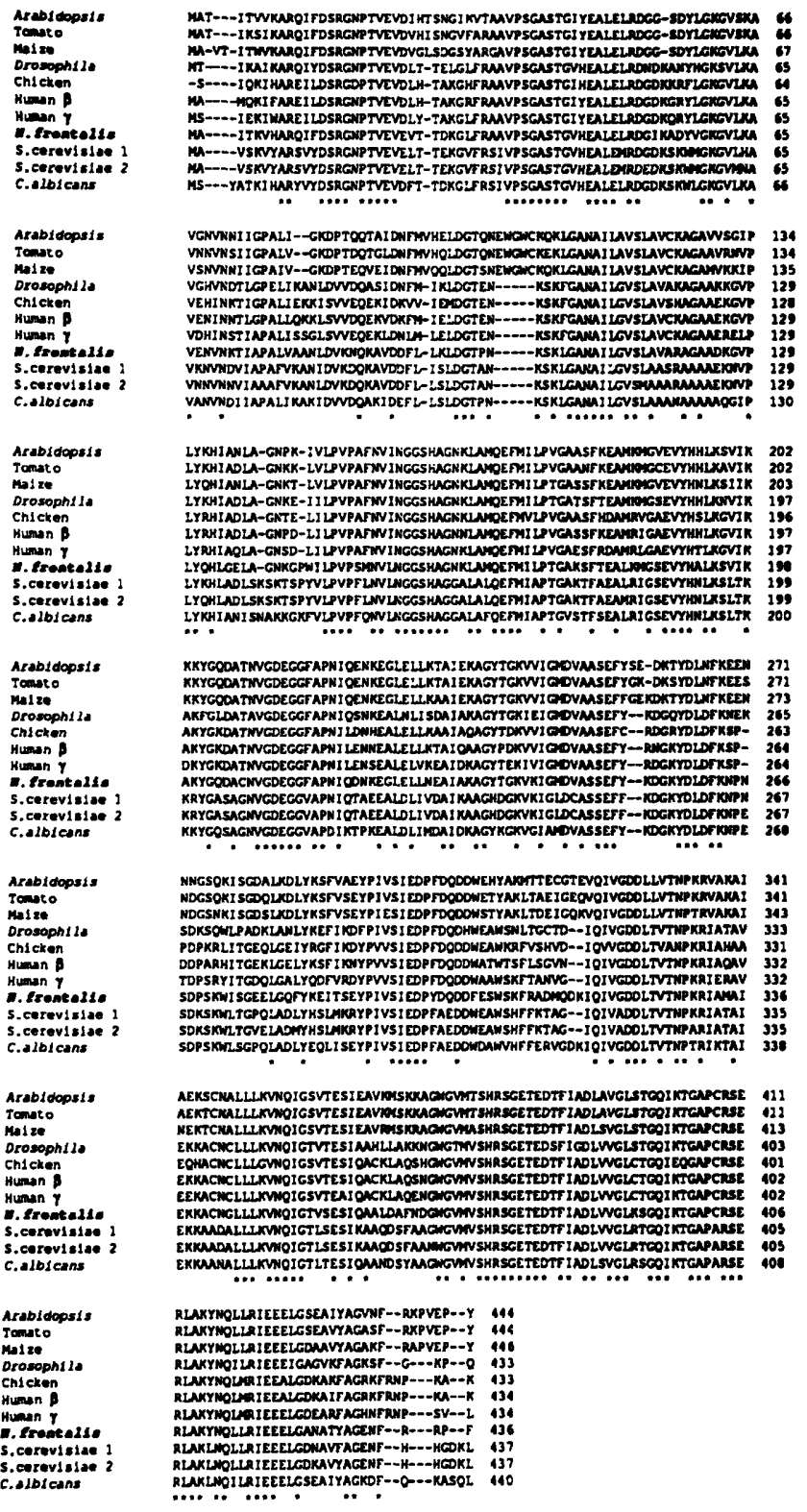

Fig 3. Amino acid alignment of $N$. frontalis enolase with eukaryotic enolases. Asterisks indicate identical residues in the 11 sequences. Dashes indicate gaps created by the TREEALIGN program of Bisance (Dessen et al., 1990).

charidases), and maltose or lactose as carbon sources. The size of the enol transcript predicted from the knowledge of the coding sequence is about $1600 \mathrm{nt}$. Equal amounts of total cellular RNAs from the different cultures were analysed by Northern blotting using a probe for the enol coding sequence. The $N$. frontalis enolase mRNA was detected as an abundant single transcript of $1.6 \mathrm{~kb}$ (Fig. 6). The expression levels of enol were quite similar when the fungus was grown on glucose, methylglucose, maltose or lactose. However, the amount of enol mRNA from mycelium grown on crystalline cellulose (Avicel) was tenfold lower. In the presence of cellulose, the fungal biomass was quite similar to the biomass obtained on
Table 2. Percentage amino acid identity between different eukaryotic enolases

\begin{tabular}{|c|c|c|c|c|c|c|c|c|c|c|c|}
\hline & 1 & 2 & 3 & 4 & 5 & 6 & 7 & 8 & 9 & 10 & 11 \\
\hline $1 N$. frontalis & & 70 & 71 & 70 & 70 & 70 & 70 & 68 & 73 & 70 & 70 \\
\hline $2 C$ albicans & & & 78 & 76 & 63 & 64 & 63 & 62 & 66 & 65 & 65 \\
\hline 3 S. cerevisiae 1 & & & & 95 & 61 & 61 & 60 & 61 & 65 & 64 & 62 \\
\hline 4 S. cerevisiae 2 & & & & & 60 & 61 & 59 & 59 & 63 & 63 & 61 \\
\hline 5 Tomato & & & & & & 87 & 90 & 66 & 70 & 71 & 72 \\
\hline 6 Maize & & & & & & & 86 & 65 & 67 & 69 & 69 \\
\hline 7 Arabidopsis & & & & & & & & 66 & 69 & 70 & 70 \\
\hline 8 Chicken & & & & & & & & & 70 & 85 & 80 \\
\hline 9 Drosophila & & & & & & & & & & 72 & 72 \\
\hline 10 Human $\beta$ & & & & & & & & & & & 83 \\
\hline 11 Human $\gamma$ & & & & & & & & & & & \\
\hline
\end{tabular}

The NBRF accession numbers for enolases are indicated in brackets. $1, N$. frontalis; 2, C. albicans (A45241); 3, S. cerevisiae ENO1 (NOBY); 4, S. cerevisiae ENO2 (NOBY2); 5, tomato (JQ1185); 6, maize (S16257); 7, Arabidopsis thaliana (JQ1187); 8, chicken (A23850); 9, Drosopbila melanogaster (S07586); 10, human $\beta$ form (S06756); 11, human $\gamma$ form (NOHUG).

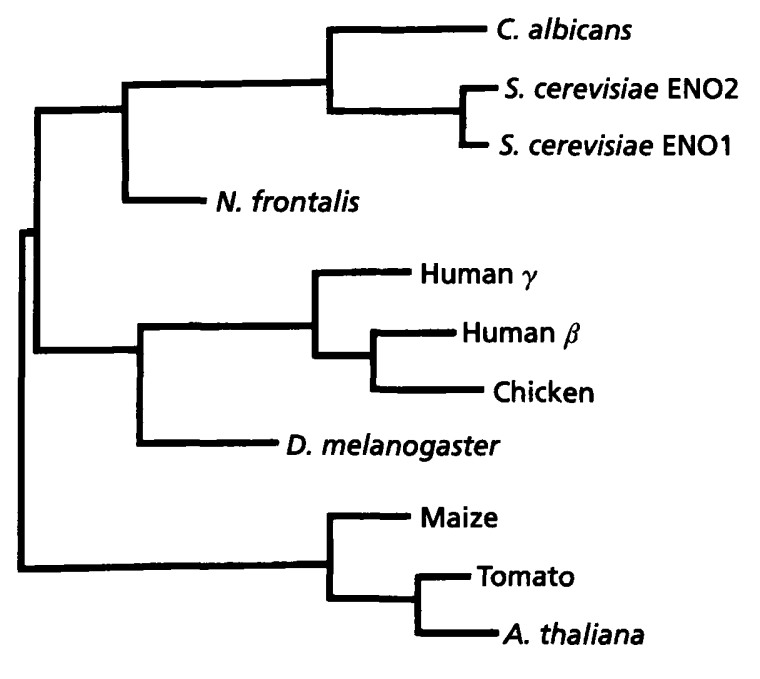

Fig 4. Phylogenetic relationships between eukaryotic enolases. The dendrogram was established from the multiple alignment seen in Fig. 3 using the parsimony method (Hein, 1990) from the TREEALIGN program of Bisance (Dessen et al., 1990).

other carbon sources. Furthermore, the levels of rRNA detected with the $16 \mathrm{~S}$ rRNA probe were similar in the different culture conditions (data not shown).

\section{DISCUSSION}

In this paper we report the cloning and characterization of the first enolase gene (enol) from a filamentous fungus, $N$. frontalis. A cDNA clone was first isolated and identified by the high degree of similarity to the enolase genes from other organisms, but this $1.3 \mathrm{~kb}$ clone was found to be 
(a)

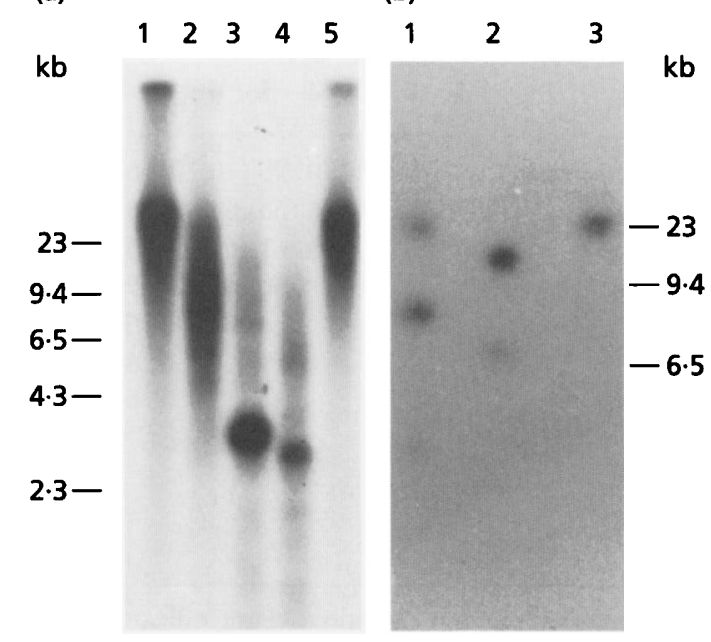

Fig 5. Southern hybridization of $N$. frontalis enolase to restricted genomic DNAs. (a) $N$. frontalis genomic DNA was digested with BamHI (1), Xbal (2), EcoRI (3), HindIII (4) or was undigested (5). The probe was the $2.4 \mathrm{~kb}$ Xbal-HindIII fragment overlapping the coding part and the $5^{\prime}$ non-coding part of the genomic clone. (b) $S$. cerevisiae genomic DNA was digested with BamHI (1), Xbal (2) or was undigested (3). The probe was the $1.3 \mathrm{~kb}$ partial enolase cDNA clone pPR6.1. The sizes of marker DNA fragments are indicated at the sides.

(a)

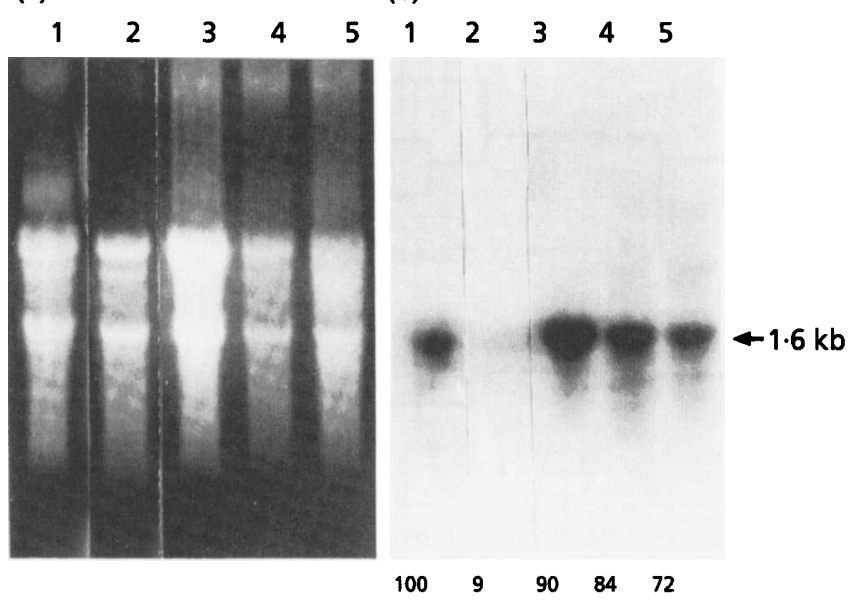

Fig 6. Analysis of $N$. frontalis enolase expression after growth on different carbon sources. (a) Total RNAs ( $30 \mu \mathrm{g}$ per lane) from $N$. frontalis grown on glucose (1), Avicel (2), methylglucopyranoside (3), maltose (4) and lactose (5) were separated on agarose gel. (b) Identification of the enol gene transcript was obtained by probing total RNAs with the partial CDNA enolase clone PPR6.1. The numbers under each lane indicate the level of expression obtained by densitometric analysis after re-probing the blot with a rRNA probe. The ratio of the signal for enol mRNA to that for rRNA was taken as $100 \%$ for glucose-grown mycelium.

incomplete: the part of the sequence encoding the $\mathrm{N}$ terminal amino acids of the expected protein was missing (Reymond et al., 1992). A large number of positive clones were isolated from several rounds of hybridization of cDNA libraries, but all the analysed clones were the same size. This feature may be common to enolase cDNAs, as clones isolated from other organisms appeared to be incomplete. In C. albicans, Franklin et al. (1990) have isolated a partial cDNA clone, and in $P$. falciparum, Read et al. (1994) have isolated a $1.3 \mathrm{~kb}$ enolase cDNA and used the $5^{\prime}$ rapid amplification of cDNA ends (RACE) technique to isolate a complete cDNA clone. It is possible that in these different organisms the primary structure of the enolase genes leads to the formation of strong secondary structures in the mRNA, producing a pause in the reverse transcription reaction during $\mathrm{cDNA}$ synthesis.

Comparison of the predicted amino acid sequence of the $N$. frontalis enolase with enolase sequences from other eukaryotes shows a high degree of evolutionary conservation (Fig. 3). Homology has been retained throughout the protein and 187 amino acids arranged in short tracts are conserved in the eleven enolase sequences analysed. Enolase sequences from Bacillus and $P$. falciparum, sharing 53.5 and $63 \%$ homology, respectively, with $N$. frontalis enolase, were excluded from the alignment studies.

$N$. frontalis possesses a single enolase gene as confirmed by Southern blotting (Fig. 5), and the catalytically active enzyme must therefore be a homodimer of the enolase gene product. In higher eukaryotes the expression of enolase isoenzymes are specific for a cell type or a developmental stage of the organism (Segil et al., 1988). In $S$. cerevisiae, the expression of ENO1 ensures that glycolysis continues when the environmental conditions do not favour expression of ENO2 (McAlister \& Holland, 1982). However, C. albicans (Brett Mason et al., 1993) and $N$. frontalis appear to have only a single enolase gene. These two organisms are adapted to special ecological niches, the human body and the rumen, where the environmental conditions are relatively constant and this may explain the pattern of expression of the enolase gene.

Studies of DNA base composition from $N$. frontalis and other anaerobic fungi have demonstrated these organisms to have the most $\mathrm{A}+\mathrm{T}$-rich genome of any organisms identified so far (Billon-Grand et al., 1991; Brownlee, 1994). Evidence was presented that the A+T-rich sequences are widely spread in the genome as repeated sequences and spacer regions of DNA flanking the highly repeated rRNA coding regions. From our present study on enolase gene organization and from the characterization of several cDNA clones of $N$. frontalis, phosphoenolpyruvate carboxykinase (Reymond et al., 1992), $\beta$-succinyl-CoA synthetase (T. H. C. Brondijk, personal communication), xylanase 1 and xylanase 2 (R.D., unpublished results), it could be postulated that the coding sequences of the genes from $N$. frontalis are separated in the genome by long stretches of very $\mathrm{A}+\mathrm{T}$ rich flanking sequences (less than $15 \mathrm{~mol} \% \mathrm{G}+\mathrm{C}$ ). Moreau et al. (1982) reported a general pattern of organization of DNA in eukaryotic genomes whereby $\mathrm{A}+\mathrm{T}$-rich 'linker' sequences systematically punctuate regions that contain coding sequences and might be 
involved in DNA functional organization at the chromosome level. Brownlee (1994) pointed out that the very A + T-rich genome of $N$. frontalis might be expected to affect the amino acid composition of the encoded proteins. Clearly the amino acid sequence comparisons with eukaryotic enolases (Fig. 3) demonstrate that this is not the case, as 269 residues ( $63 \%$ of the total amino acids) are invariant or similar.

The codon usage observed in $N$. frontalis enol gene was biased since only 36 codons out of the 61 sense codons were used. This codon preference (Table 1 ) is very close to that of the enolase from $C$. albicans (Sundstrom \& Aliaga, 1992), where 35 codons were used. The only minor differences were that the $N$. frontalis gene utilized AAT for Asn, GAT for Asp, CAT for His, TTT for Phe and TAT for Tyr more frequently (Table 1 ), whereas in $C$. albicans, the last $T$ was replaced by a $C$ in the same codons except for Leu (TTG). However, the P. falciparum enolase showed a lower codon usage bias as 46 codons were used. The codons always ended in $\mathrm{A}$, reflecting the $36 \mathrm{~mol} \% \mathrm{G}+\mathrm{C}$ content of the coding sequence. In the $p 190$ gene of $P$. falciparum the coding area had an $\mathrm{A}+\mathrm{T}$ content of $74 \mathrm{~mol} \%$ (Mackay, 1987). In the filamentous fungi N. crassa and Aspergillus nidulans, highly expressed genes tend on the whole to show more marked codon bias than those expressed at a low level (Gurr et al., 1987). The high degree of codon bias for $N$. frontalis enol is consistent with it being a highly expressed gene using the most abundant isoacceptor tRNAs.

The enol gene presents other features characteristic of filamentous fungal genes. The enolase gene was interrupted by a $331 \mathrm{bp}$ long intervening sequence. The introns of filamentous fungi are generally short, on average less than 100 bp (Gurr et al., 1987), although in Neurospora crassa some are as large as 691 bp (Edelmann \& Staben, 1994). The enol gene intron boundaries followed the consensus sequences GTANGT and PyAG determined for filamentous fungal genes (Gurr et al., 1987). All these results show that the remarkably low overall $G+C$ content in an anaerobic fungus does not affect the gene organization which is similar to that in aerobic fungi.

$N$. frontalis enolase mRNA was detected as an abundant transcript in mycelia grown on glucose or on the disaccharides maltose or lactose (Fig. 6). However, when the fungus was grown on glucose the level of the enolase transcript was tenfold higher than that detected in cellulose-grown mycelia. These results are reminiscent of the 20 -fold glucose-mediated induction of the $S$. cerevisiae ENO2 gene (McAlister \& Holland, 1992). In C. albicans, the level of enolase transcripts was sixfold higher in glucose-grown cells than in cells grown on a gluconeogenic carbon source (Brett Mason et al., 1993)

\section{Concluding remarks}

The cloning and characterization of the enol gene from a genomic clone containing 5 'flanking sequences greater than $1.5 \mathrm{~kb}$ will allow the characterization of the enolase gene promoter. Promoters of highly expressed genes such as 3-phosphoglycerate kinase (Takaya et al., 1994) have been useful for the construction of transformation vectors. Preliminary experiments have shown that the transformation of oomycetes or $N$. frontalis are unsuccessful using regulatory sequences from higher fungi. The presence of homologous promoting sequences in the transformation vectors should allow the efficient transformation of anaerobic fungi.

\section{REFERENCES}

Billon-Grand, G., Fiol, J. B., Breton, A., Bruyère, A. \& Oulhaj, Z. (1991). DNA of some anaerobic fungi: $G+C$-content determination. FEMS Microbiol Lett 82, 267-270.

Brett Mason, A., Buckley, H. R. \& Gorman, J. A. (1993). Molecular cloning and characterization of the Candida albicans enolase gene. $J$ Bacteriol 175, 2632-2639.

Brownlee, A. G. (1994). The nucleic acids of anaerobic fungi. In Anaerobic Fungi Biology, Ecology and Function, pp. 124-136. Edited by D. O. Mountfort \& C. G. Orpin. New York: Marcel Dekker.

Carmen, A. A. \& Holland, M. J. (1994). The upstream repression sequence from the yeast enolase gene ENO1 is a complex regulatory element that binds multiple trans-acting factors including REB1. $J$ Biol Cbem 269, 9790-9797.

Chirgwin, J. M., Przybyla, A. E., MacDonald, R. J. \& Rutter, W. S. (1979). Isolation of biologically active ribonucleic acid from sources enriched in ribonuclease. Biochemistry 18, 5294-5297.

Cohen, R., Holland, J. P., Yokoi, T. \& Holland, M. J. (1986). Identification of a regulatory region that mediates glucosedependent induction of the Sacharomyces cerevisiae enolase gene ENO2. Mol Cell Biol 6, 2287-2297.

Cohen, R., Yokoi, T., Holland, J. P., Pepper, A. E. \& Holland, M. J. (1987). Transcription of the constitutively expressed yeast enolase gene ENO1 is mediated by positive and negative cis-acting regulatory sequences. Mol Cell Biol 7, 2753-2761.

Dessen P., Fondrat, C., Valencien, C. \& Mugnier C. (1990). Bisance: a French service for access to biomolecular sequence databases. Cabios 6, 355-356.

Edelmann, S.E. \& Staben, C. (1994). A statistical analysis of sequence features within genes from Neurospora crassa. Exp Mycol 18, 70-81.

Feinberg, A. P. \& Vogelstein, B. (1983). A technique for radiolabelling DNA restriction endonuclease fragments to high specific activity. Anal Biochem 132, 6-13.

Franklyn, K. M., Warmington, J. R., Otta, A. K. \& Ashman, R. B. (1990). An immunodominant antigen of Candida albicans shows homology to the enzyme enolase. Immunol Cell Biol 68, 173-178.

Gurr, S. J., Unkles, S. E. \& Kinghorn, J. R. (1987). The structure and organization of nuclear genes of filamentous fungi. In Gene Structure in Eukaryotic Microbes, pp. 93-139. Edited by J. R. Kinghorn. Oxford: IRL Press.

Hébraud, M. \& Fèvre, M. (1988). Characterization of glycoside and polysaccharide hydrolases secreted by the rumen anaerobic fungi Neocallimastix frontalis, Sphaeromonas communis and Piromonas communis. J Gen Microbiol 134, 1123-1129.

Hein, J. (1990). Unified approach to alignment and phylogenies. Methods Enzymol 183, 626-645.

Holland, M. J., Holland, J. P., Thill, G. P. \& Jackson K. A. (1981). The primary structures of two yeast enolase genes. $J$ Biol Chem 256, 1385-1395.

Johnston, P. (1988). Yeast genetics: molecular aspects. In Yeast: a Practical Approach, pp. 107-123. Edited by I. Campbell \& J. Duffus. Oxford: IRL Press. 
Lebioda, L., Stec, B. \& Brewer, J. M. (1989). The structure of yeast enolase at $2 \cdot 25$ - $\AA$ resolution: an 8-fold $\beta+\alpha$-barrel with a novel $\beta \beta \alpha \alpha(\beta \alpha)_{6}$ topology. $J$ Biol Chem 264, 3685-3693.

Li, J. \& Heath, I. B. (1993). Chytridiomycetous gut fungi, oft overlooked contributors to herbivore digestion. Can J Microbiol 39, 1003-1013.

Lowe, S. E., Theodorou, M. K. \& Trinci, A. P. J. (1987). Cellulases and xylanases of an anaerobic rumen fungus grown on wheat straw, wheat straw holocellulose, cellulose and xylan. Appl Environ Microbiol 53, 1216-1223.

McAlister, L. \& Holland, M. J. (1982). Targeted deletion of a yeast enolase structural gene. J Biol Chem 257, 7181-7188.

Mackay, M. (1987). Gene organization in Plasmodium falciparum. In Gene Structure in Eukaryotic Microbes, pp. 227-241. Edited by J. R. Kinghorn. Oxford: IRL Press.

Maniatis, T., Fritsch, E. F. \& Sambrook, J. (1982). Molecular Cloning: a Laboratory Manual. Cold Spring Harbor, NY: Cold Spring Harbor Laboratory.

Marvin-Sikkema, F. D., Pedro Gomes, T. M., Grivet, J. P., Gottschal, J. C. \& Prins, R. A. (1993). Characterization of hydrogenosomes and their role in glucose metabolism of Neocallimastix sp. L2. Arch Microbiol 160, 388-396.

Moreau, J., Marcand, L., Maschat, F., Kejzlarova-Lepesant, J., Lepesant, J. A. \& Scherrer, K. (1982). A + T-rich linkers define functional domains in eukaryotic DNA. Nature 295, 260-262.

Orpin, C. G. (1975). Studies on the rumen flagellate Neocallimastix frontalis. J Gen Microbiol 91, 249-262.

Read, M., Hicks, K. E., Sims, P. F. G. \& Hyde, J. E. (1994). Molecular characterization of the enolase gene from the human malaria parasite Plasmodium falciparum. Evidence for ancestry within a photosynthetic lineage. Eur J Biochem 220, 513-520.

Reymond, P., Durand, R., Hébraud, M. \& Fèvre, M. (1991). Molecular cloning of genes from the rumen anaerobic fungus
Neocallimastix frontalis: expression during hydrolase induction. FEMS Microbiol Lett 77, 107-112.

Reymond, P., Geourjon, C., Roux, B., Durand, R. \& Fèvre, M. (1992). Sequence of the phosphoenolpyruvate carboxykinaseencoding cDNA from the rumen anaerobic fungus Neocallimastix frontalis: comparison of the amino acid sequence with animals and yeast. Gene 110, 57-63.

Sanger, F., Nicklen, S. \& Coulson, A. R. (1977). DNA sequencing with chain-terminating inhibitors. Proc Natl Acad Sci USA 74, 5463-5467.

Segil, N., Shrutkowski, A., Dworkin, M. B. \& Dworkin-Rastl, E. (1988). Enolase isoenzymes in adult and developing Xenopus laevis and characterization of a cloned enolase sequence. Biochem $J$ 251, 31-39.

Sundstrom, P. \& Aliaga, G. R., (1992). Molecular cloning of cDNA and analysis of protein secondary structure of Candida albicans enolase, an abundant immunodominant glycolytic enzyme. $J$ Bacteriol 174, 6789-6799.

Takaya, N., Yanai, K., Horiuchi, H., Ohta, A. \& Takagi, M. (1994). Cloning and characterization of two $3^{\prime}$-phosphoglycerate kinase genes of Rhizopus niveus and heterologous gene expression using their promoters. Curr Genet 25, 524-530.

Van der Straeten, D., Rodrigues-Pousada, R. A., Goodman, H. M. \& Van Montagu, M. (1991). Plant enolase: gene structure, expression and evolution. Plant Cell 3, 719-735.

Zhou, L., Xue, G., Orpin, C. G., Black, G. W., Gilbert, H. J. \& Hazlewood, G. P. (1994). Intronless $c e l B$ from the anaerobic fungus Neocallimastix patriciarum encodes a modular family A endoglucanase. Biochem J 297, 359-364.

Received 19 December 1994; revised 27 February 1995; accepted 10 March 1995. 